\title{
Volumetric intracoronary ultrasound: A new maximum confidence approach for the quantitative assessment of progression-regression of atherosclerosis?
}

\author{
Clemens von Birgelen, Cornelis J. Slager, Carlo Di Mario, Pim J. de Feyter, Patrick \\ W. Serruys* \\ Thoraxcenter, Division of Cardiology, University Hospital Rotterdam-Dijkzigt and Erasmus University, Rotterdam, The Netherlands
}

\begin{abstract}
Quantitative assessment of atherosclerosis during its natural history and following therapeutic interventions is important, as cardiovascular disease remains the most significant cause of morbidity and mortality in industrial societies. While coronary angiography delineates the vessel lumen, permitting only the indirect determination of atherosclerotic wall changes encroaching upon the lumen, intracoronary ultrasound permits direct plaque assessment and quantification. The angiographic percent diameter stenosis, previously suggested as measure of a maximum confidence approach, is still commonly used to quantify stenosis severity, but the reference segments which are required for angiographic interpolation of the normal vessel dimensions are frequently involved in the general process of atherosclerosis, including progression or regression. Considering also the variability of vascular remodeling during the evolution of atherosclerosis, including compensatory enlargement and paradoxical arterial shrinkage, intracoronary ultrasound appears currently to be the only reliable technique to measure plaque burden and progression or regression of atherosclerosis. However, correct matching of the site of measurement at follow-up with the site of the initial ultrasound study is often difficult to achieve, but is significantly facilitated by the use of volumetric intracoronary ultrasound. This approach permits not only area measurement, but also measurement of plaque volume, which appears to be the ideal measure for quantifying the atherosclerotic plaque, as it is highly reproducible and directly reflects the changes of an entire arterial segment.
\end{abstract}

Keywords: Coronary artery disease; Progression-regression; Vascular remodeling; Intravascular ultrasound; Volumetric quantification; Plaque volume; Atherosclerosis; Three-dimensional reconstruction

\footnotetext{
* Corresponding author, Thoraxcenter, Bd 432, Cardiac Catheterization and Intracoronary Imaging Laboratories, P.O. Box 1738, 3000 DR Rotterdam, The Netherlands. Tel.: + 31 10436 0511; Fax: + 31104369154.
}

\section{Introduction}

Coronary artery disease $(\mathrm{CAD})$ remains the cause of death and disability in the industrialized countries, despite our increased knowledge about 
the pathogenetic mechanisms of atherosclerosis [1-5] and our subsequently increased awareness and management of unfavourable risk factors including hypercholesterolemia hypertension, obesitas, smoking and psychological stress. The search for effective interventions remains and the reliable quantitative assessment of atherosclerosis during its natural history and various therapeutical interventions is thus of paramount importance and required in order to define the efficacy of these therapeutical measures [6].

During the last two decades, coronary angiography has been considered the standard method to evaluate the coronary anatomy. The development of semi-automated quantitative angiography in the late 1970s [7] and its clinical application to interventional cardiology in the early 1980s [8] allowed the replacement of visual assessment by a semi-automated approach [9-11], providing objective and reproducible measurements of luminal dimensions. However, coronary angiography delineates only the vessel lumen as a silhouette, a perspective that is incapable of reflecting the irregular nature of the atherosclerotic vessel wall changes. Thus, plaques may be present in angiographically normal segments.

A prognostic value of angiographic endpoints has been demonstrated for both visual assessment and semi-automated coronary angiography $[12,13]$, but the limitations of angiography may explain the minimal changes in luminal dimensions observed in large angiographic studies, aimed at the assessment of progression or regression of coronary atherosclerosis during pharmacologic or dietary interventions [14]. Particularly the use of the relative percent diameter stenosis, recently suggested as the angiographic measure of a maximum confidence approach to quantify stenosis severity [15], nowadays appears to be doubtful, as the angiographic reference segments themselves are frequently involved in the general process of atherosclerosis, including progression or regression. Accordingly, new quantitative coronary imaging techniques such as intracoronary ultrasound, which permits the direct qualitative and quantitative assessment of the coronary plaque, may provide an important addition to the understanding of the natural history and prognosis of coronary atherosclerosis as well as the potential of pharmacological interventions $[11,16,17]$

\section{Current angiographic measures and their limitations}

The distribution of atherosclerosis can be either focal or diffuse [18]. If the process of atherosclerosis is predominantly diffuse, relative measurements are unable to quantify plaque severity, explaining the findings of several pathologic studies which indicate that angiography may underestimate the extent and severity of the atherosclerotic changes [19-22]. The angiographic percent diameter stenosis [15] is commonly used to quantify stenosis severity, but the 'normal' reference segments which are required for the calculation of the relative lumen diameter stenosis are frequently involved in a general process of atherosclerosis including progression or regression, thus suggesting pseudo-progression or pseudo-regression [11,23-25]. Furthermore, a relative parameter does not accurately reflect the functional significance of the lesion [26], since lẹsion length and absolute luminal dimensions are not taken into account. Indeed, such an approach to quantify progression or regression of atherosclerosis appears to be far away from 'a maximal confidence'.

'Absolute measurements such as minimal or mean luminal diameter generally appear to be superior indicators of stenosis severity [27-29] or progression of atherosclerosis [30]. However, the minimal luminal diameter which is the most important determinant of the functional significance of coronary stenoses $[26,27]$ is also crucial, since an increase of the lumen diameter at the site of the minimal luminal cross-section can be associated with an overall reduction of the mean lumen diameter. Nevertheless, the mean lumen diameter is the best angiographic measure to determine progression or regression of diffuse atherosclerosis of entire coronary segments [23].

\section{Potential and limitations of two-dimensional intracoronary ultrasound}

Intracoronary ultrasound is a relatively new method which provides cross-sectional images of both the vessel lumen and wall. The size of the ultrasound transducers had gradually been re- 
duced so that recently introduced ultrasound catheters have a distal tip diameter of even less than $1 \mathrm{~mm}$.

The sensitivity of intracoronary ultrasound in detecting minimal atherosclerosis is superior to angiography [31-35] and additional qualitative information on the plaque composition [31,36-40] is provided. Plaque thickness can be directly quantified by ultrasound [41], a feature which was first utilized during epicardial high-frequency ultrasound imaging [42], a forerunner of intracoronary ultrasound. Direct measurement of the vascular dimensions by intracoronary ultrasound can nowadays be performed with high accuracy [31]. Finally, the safety of the invasive intracoronary ultrasound examination, particularly if performed during diagnostic catheterization [43], should be emphasized.

Many problems of the first generation intracoronary ultrasound catheters have been solved or minimized and the image quality has been significantly improved, but the angle of incidence of the ultrasonic beam is still important, since a noncoaxial position of the transducer may result in a distortion of the ultrasound image [44]. Plaque compression by the ultrasound catheter at vessel curvatures and the lateral or out-of-plane resolution of current ultrasound transducers remain fields of future improvement [45].

\section{Insights gained from studies of vascular remodeling}

Coronary angiography detects atherosclerotic changes in the vessel wall only if the plaque encroaches the lumen. This does not occur during the early stage of plaque expansion as demonstrated by Armstrong et al., who detected in monkeys during an atherogenic diet an enlargement of the coronary artery in response to luminal encroachment by the coronary plaque [46-48]. These experimental findings were confirmed by Glagov et al. [46] in human coronary arteries, demonstrating in histological sections of the arteries an enlargement of the total vessel area as plaque area increases. This mechanism appears to be capable of compensating for an increase of plaque burden until the plaque occupies 40 percent of the internal elastic membrane area.

As a consequence of the compensatory enlargement of the vessel, luminal area may be preserved, as seen angiographically despite extensive CAD. Stiel et al. confirmed in a study comparing postmortem quantitative angiography with morphometric analysis on histologic sections of the coronary arteries that compensatory enlargement of diseased coronary segments results in a significant angiographic underestimation of coronary atherosclerosis during the early stage of the disease [49].

The compensatory enlargement of the coronary arteries during the early progression of atherosclerosis does not represent any problem for the quantitative assessment by intracoronary ultrasound. The method itself can even be used to study the mechanism of the arterial remodeling [50]. Ultrasonic confirmation of the compensatory enlargement during evolving atherosclerosis was first performed non-invasively, using epicardial highfrequency echocardiography [51] and carotid duplex scanners [52], and was subsequently demonstrated by intravascular ultrasound in coronary [53-55] and femoral arteries [56].

Thus, coronary angiography is unable to detect and quantify the early stage of evolving atherosclerosis, while intracoronary ultrasound permits direct inspection and measurement of the plaque burden without need for interpolation or reference segments, clearly demonstrating its superiority in assessing the early phase of atherosclerosis.

In order to correct the angiographic measurement of the percent diameter stenosis during later stages of atherosclerosis, a correction for the compensatory enlargement of the artery could theoretically be performed, if coronary remodeling occurs in all arteries in the same way. However there is evidence that some arteries show remodeling while others do not enlarge and even seem to show a reverse modeling. Such a 'paradoxical arterial wall shrinkage' has been described by Pasterkamp et al. in human atherosclerotic femoral arteries [57]. It remains unclear in how many cases this 'reverse Glagovian modeling' accounts for or contributes to the luminal narrowing. Current concepts of vascular remodeling are based on a complex interaction between growth 
factors, vasoactive substances, pressure, flow, and shear stress, while the endothelium plays an important role as the sensor and transducer of signals $[50,58-60]$. Disturbance of this balance or the enlargement of the distal post-stenotic reference segment may result in 'arterial shrinkage'.

Our experience with three-dimensional intracoronary ultrasound (Fig. 1) demonstrates that a reverse vascular modeling also occurs in coronary arteries. In this light, a correction of the percent diameter stenosis, measured by quantitative coronary angiography, appears to be highly questionable. If there is such a variability of vascular remodeling and if the plaque may grow inside or outside of the coronary lumen, intracoronary ul- trasound appears to be currently the only reliable technique which permits a direct measurement of plaque burden and progression or regression of atherosclerosis.

\section{The benefit of the third dimension in intracoronary ultrasound}

After the introduction of intracoronary ultrasound in research and clinical use, a substantial role of this technique in the assessment of progression or regression of coronary atherosclerosis will be expected. Indeed, the accuracy [61] and in vivo feasibility $[62,63]$ of intracoronary ultrasound has been well demonstrated in experimental stud-

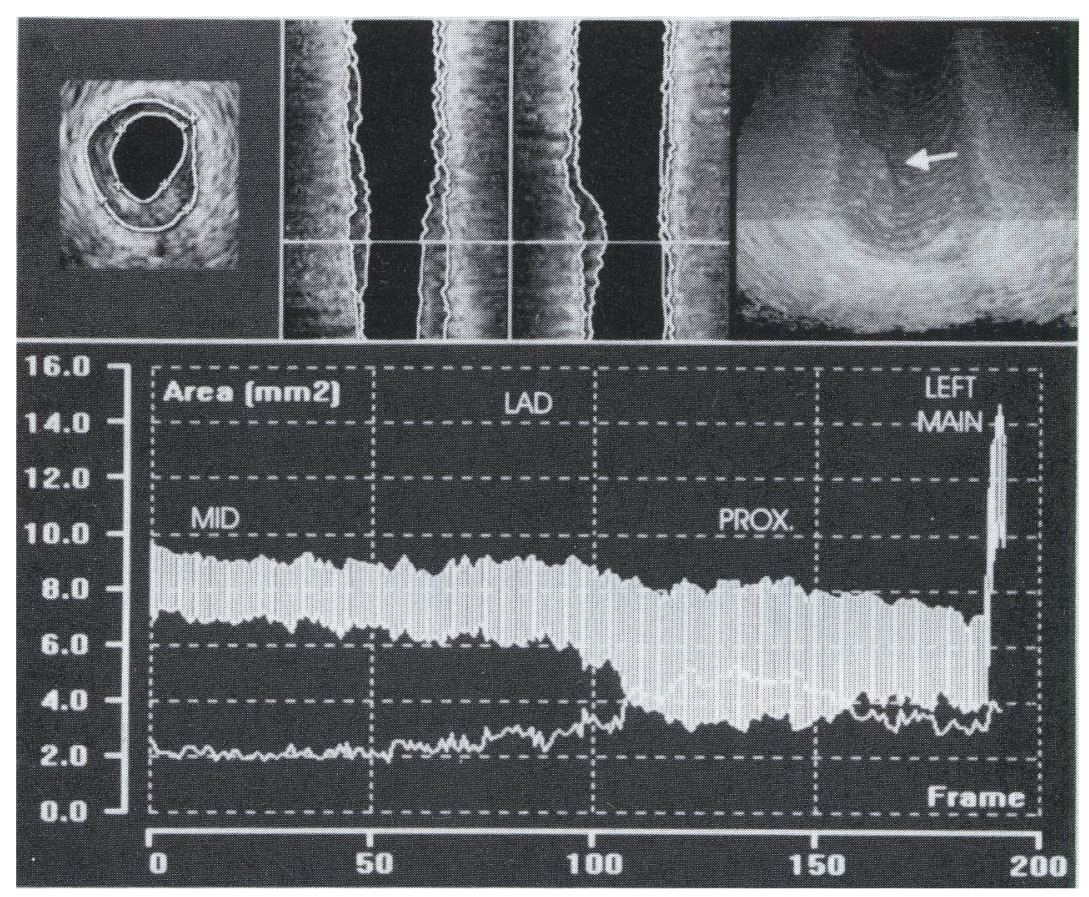

Fig. 1. Primary lesion in the proximal segment of the left anterior descending coronary artery (LAD), assessed by a new system for quantitative analysis of three-dimensional intracoronary ultrasound images. The cross-sectional ultrasound images, representing a segment of round $10 \mathrm{~mm}$ length, were reconstructed in two perpendicular longitudinal sections (mid panels). A computerized contour detection was performed providing a three-dimensional view (right upper panel; arrowhead indicates target stenosis) and area measurements $\left(\mathrm{mm}^{2}\right)$ of the lumen, plaque, and total vessel on 200 consecutive ultrasound frames (lower panel). The values of the plaque area are shown as a white field between two lines, representing the absolute values of the total vessel and lumen areas. The absolute value of the plaque area can be derived from this white field, but is also displayed as a single white line. The area stenosis at the site of the mid segment of the LAD was round $20 \%$. According to the mechanism described by Glagov, an enlargement of the total vessel area, partly compensating the plaque burden, may be expected at the site of a relatively focal plaque. In the measurement display of this case, however, a paradoxical reduction of the total vessel area from the distal reference in the early mid LAD (MID) to the target stenosis in the proximal segment (PROX) was observed. Plaque volume of the entire arterial segment was $32 \mathrm{~mm}^{3}$. 


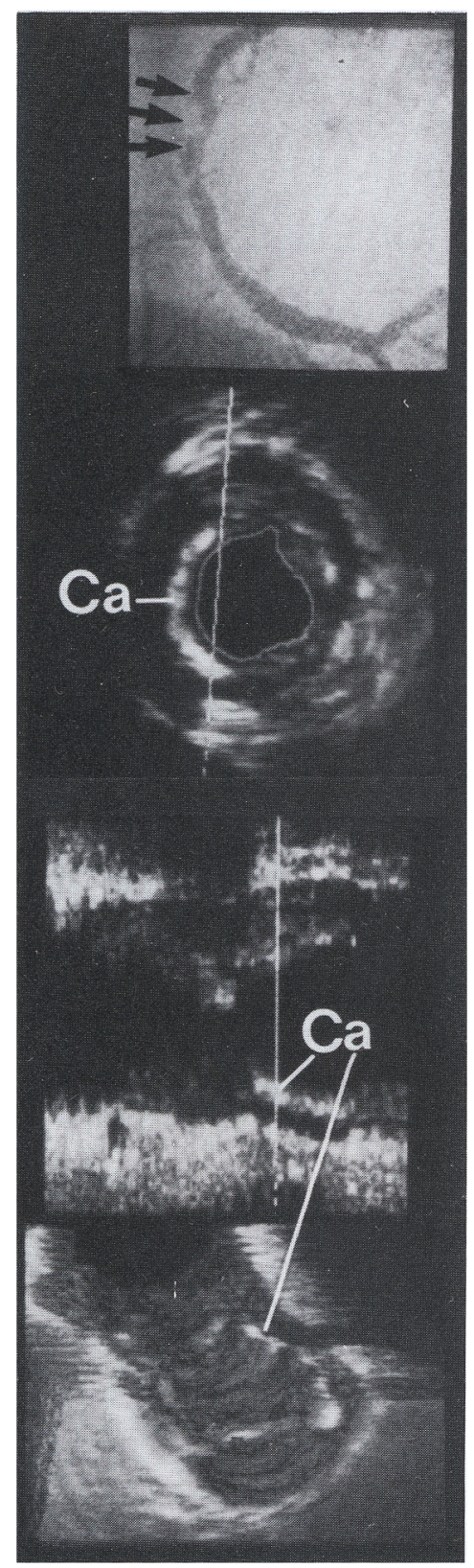

Fig. 2. Calcified lesion in a mid right coronary artery. Arrowheads in the angiogram indicate the segment which was reconstructed. The superficial calcification is visible in the cross-sectional, longitudinal, and three-dimensional cylindrical view (upper mid, lower mid, and low panel respectively). The longitudinal and cylindrical displays permit a much more comprehensive insight into the complex spatial distribution of the plaque. ies of progression or regression of atherosclerosis. The principal reason why this technique has not yet been introduced to major human progression-regression trials are the difficulties with correctly matching the sites of measurement in serial ultrasonic studies [62-70], but a reliable serial evaluation of progression or regression of atherosclerosis depends critically on the correct matching of the images. This limitation results from the lack of the third dimension in conventional two-dimensional ultrasound [67]. This procedure can be significantly facilitated by the use of three-dimensional reconstruction of intracoronary ultrasound images, permitting in serial ultrasound studies the assessment of the same site of the artery.

\section{Volumetric intracoronary ultrasound}

Three-dimensional reconstruction of intracoronary ultrasound images was first used [71] to visually assess the spatial configuration of atherosclerotic plaques (Fig. 2). Examination of dissections and stents by this technique has provided valuable clinical information [72-76].

The basic cross-sectional intracoronary ultrasound images are acquired while the ultrasound catheter is pulled back through the coronary artery segment of interest. A continuous pull-back at a uniform speed resulting in an equidistant spacing of adjacent images [77] is still the most common approach. A stepping motor, developed at the Thoraxcenter, performs an electrocardiogram (ECG)-gated withdrawal of the ultrasound catheter and can also be used to perform an ECG-gated image acquisition [78]. This approach allows to minimize artifacts induced by the cyclic movement of the ultrasound catheter in the lumen and the systolic-diastolic pulsation of the vessel wall.

Subsequently, the stack of cross-sectional images is reconstructed. The reconstruction systems differ mainly in the image segmentation, a processing step which performs a distinction between vessel wall structures and the blood-pool. The semi-automated detection facilities of commercial analysis systems are limited to the distinction between the bloodpool in the lumen and the vessel wall [71,79-83]. They are based on the definition of grey-level thresholds or acoustic quantification (Fig. 3): 


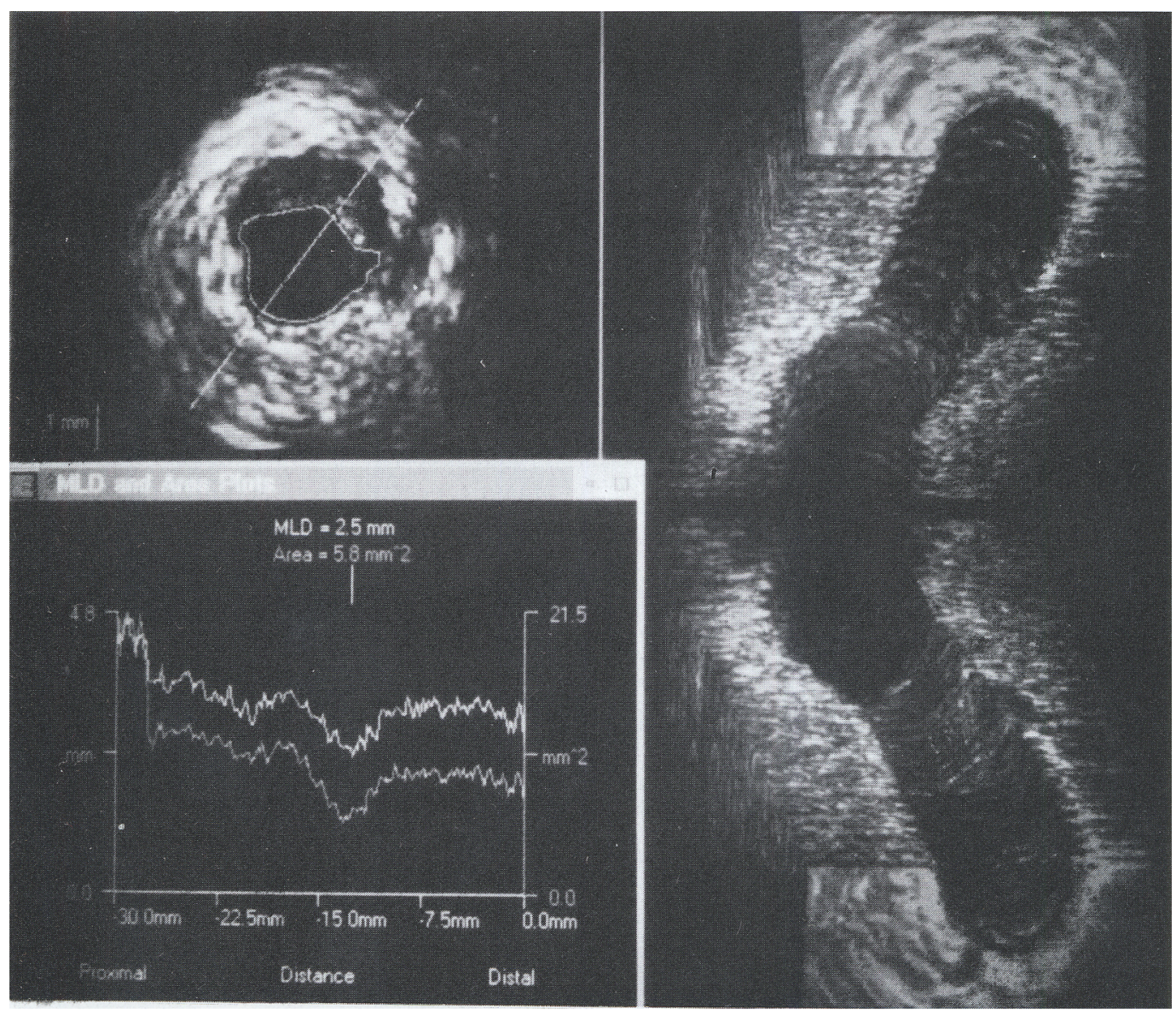

Fig. 3. Three-dimensional reconstruction of a short eccentric atherosclerotic plaque of relatively low echogenicy in the proximal segment of a coronary artery. A semi-automated distinction between the blood-pool and the vessel wall was performed by an acoustic quantification method, based on the recognition of the blood speckle, which shows a quite uniform pattern in the vessel wall and a varying pattern in flowing blood. Measurement of the lumen area and the mean luminal diameter are displayed in the left lower panel. Currently, no automated measurements of plaque area or volume can be performed by this approach.

At the Thoraxcenter, a computerized analysis system has been developed which performs a contour detection, based on the application of a minimum cost algorithm, and permits the identification of both the boundaries between the lumen and plaque as well as the plaque-media complex and adventitia (Fig. 1) using the complete volumetric information of the stack of intracoronary ultrasound images $[68,84]$. During the interactive contour detection on the longitudinal images, dynamic programming techniques are used to permit frequent up-dates of the displays including a crosssectional plus two longitudinal views (Fig. 4). The visual information from both the cross-sectional and the longitudinal views facilitates the detection of the external boundary of the vessel wall. The advantage of this approach is particularly evident if calcium or stent struts obscure parts of the underlying vessel wall, rendering the morphometric measurement on sole cross-sectional images impossible. Even with short circumferential calcifications of the plaque, a reliable interpolation of the external vessel contour can be performed. The longitudinal contours guide the otherwise automated contour detection on the cross-sectional images, which is finally checked and may be manually corrected. Using the whole set of volumetric information, the analysis system performs a semi- 


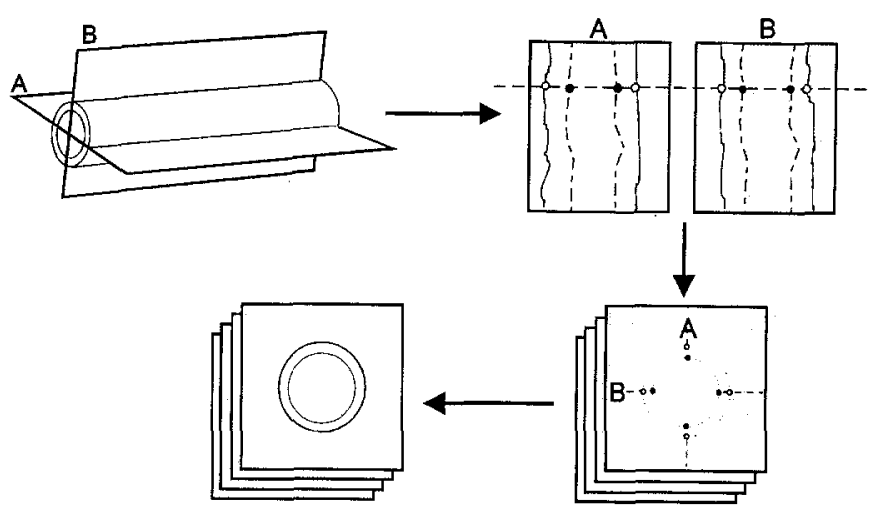

Fig. 4. Principle of the contour detection method, developed at the Thoraxcenter $[68,84,85]$. The intracoronary ultrasound images, obtained during a motorized pull-back of the ultrasound catheter, are used to reconstruct two longitudinal sections from the voxel space (voxel = volume unit). An automated contour detection of the intimal leading edge and the external boundary of the vessel is performed, based on the application of a minimum-cost algorithm, dynamic programming techniques, and user interaction. The longitudinal contours are represented as individual edge points in the whole stack of cross-sectional images. These points define center and range of the final contour detection process on the cross-sectional ultrasound images. Finally, the contours are checked and may be corrected. The analysis system provides information about areas, mean diameters and volumes of the lumen, total vessel and plaque (Fig. 1).

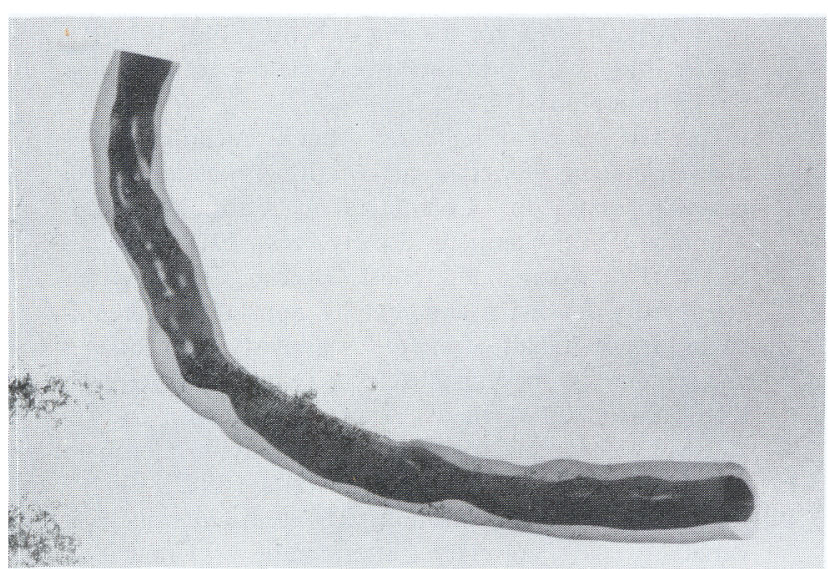

Fig. 5. Combined use of biplane angiography and three-dimensional intracoronary ultrasound by ANGUS, a new method which allows the analysis of the true geometry of the vessel lumen and plaque, taking vessel curvatures and catheter bends into account [88]. A reconstruction of a diseased right coronary artery is displayed in a frontal projection. Ultrasound data provided by the contour detection method were spatially arranged and interpolated, using biplane data on both the pull-back trajectory and the angiogram.

automated measurement of plaque volume. It reflects a function of the plaque area over the length of the reconstructed segment and can be calculated as the mean plaque area times the length of the reconstructed segment. Minimal differences in the start and end in repeated studies are unlikely to impair the accuracy of the changes in plaque volume measurements, assessed for an entire coronary arterial segment.

Volumetric measurements by the Thoraxcenter analysis system have been studied in a phantom in vitro showing a high accuracy [68]. The volumetric measurement has a lower intraobserver and interobserver variability than the measurement of areas on individual cross-sectional images [85], reflecting an averaging of the differences of the area measurement. Measurement of plaque volume [68-70,86] is particularly promising to quantify atherosclerotic plaques in progression-regression trials since it directly reflects changes of the plaque burden of an entire arterial segment with a high reproducibility.

\section{Perspective of volumetric intracoronary ultrasound}

Some limitations of three-dimensional reconstruction remain [67], but artifacts resulting from the movement of the ultrasound catheter during the cardiac cycle and systolic-diastolic changes in vessel dimensions can be minimized by the use of an ECG-gated pull-back system $[67,87]$. 
Combined use of biplane angiography and three-dimensional intracoronary ultrasound by a new method (ANGUS) may in the future help to analyze the true geometry of the vessel lumen and plaque, taking vessel curvatures and catheter bends into account [88]. In Fig. 5, a clinical example of a spatial reconstruction by ANGUS is given, showing a diseased right coronary artery in frontal projection. Ultrasound data on the intimal leading edge and the external boundary of the total vessel, provided by the contour detection method, were spatially arranged and interpolated, using biplane data on the pull-back trajectory and on the contrast angiogram. The example demonstrates that the external contour of the vessel provides additional information which cannot be obtained from a silhouette of the lumen which is normally provided by the angiogram [89]. This approach may permit a more distinct assessment of the progression or regression of atherosclerosis, an issue which is interesting as plaque progression or regression of the outer and inner curve of a bended coronary segment may differ significantly.

\section{Conclusions}

Coronary angiography depicts the silhouette of the vessel lumen permitting only an indirect analysis of the 'footprints' induced by the atherosclerosis of the coronary wall, not reflecting the early stage and the complex nature of the disease. Intracoronary ultrasound directly assesses and quantifies atherosclerotic plaques and is currenly the only reliable technique to measure progression or regression of atherosclerosis in the cardiac catheterization laboratory. The reliability of serial ultrasound studies can be further improved by using volumetric intracoronary ultrasound, which allows reliable and highly reproducible quantification of the plaque volume of entire arterial segments.

\section{Acknowledgements}

We gratefully acknowledge the contribution of Dr W. Li in developing the three-dimensional reconstruction system of the Thoraxcenter, the assistance of Dr A.G. Violaris in reviewing the manuscript, and the expert technical assistance of J. Ligthart, N. Bruining and E. van der Leur. Dr. C. von Birgelen is recipient of a Fellowship of the German Research Society.

\section{References}

[1] Ross R. The pathogenesis of atherosclerosis - an update. N Engl J Med 1986;314:488.

[2] Fuster V, Badimon L, Badimon JJ, Chesebro JH. The pathogenesis of coronary artery disease and the acute coronary syndromes (I). N Engl J Med 1992;326:242.

[3] Fuster V, Badimon L, Badimon JJ, Chesebro JH. The pathogenesis of coronary artery disease and the acute coronary syndromes (II). N Engl J Med 1992;326:310.

[4] Stary HC. Evolution and progression of atherosclerotic lesions in coronary arteries of children and young adults. Arteriosclerosis 1989;9(Suppl.)1:19.

[5] Ross R. The pathogenesis of atherogenesis of atherosclerosis: A perspective for the 1990s. Nature 1993;362:801.

[6] Kuller LH. Why measure atherosclerosis? Circulation 1993;87(Suppl.):II-34.

[7] Reiber JHC, Booman F, Troost GJ et al. A cardiac image analysis system: Objective quantitative processing of angiocardiograms. In: Computers in Cardiology. Los Alamitos IIEEE Computer Society Press, 1978;239.

[8] Serruys PW, Booman F, Troost GJ et al. Computerized quantitative coronary angiography applied to percutaneous transluminal coronary angioplasty: Advantages and limitations. In: Kaltenbach M, Gruntzig A, Rentrop $\mathrm{K}$ and Bussmann WD (eds). Transluminal Coronary Angiography and Intracoronary Thrombolysis, Coronary Heart Disease IV. Berlin: Springer-Verlag, 1982;110.

[9] Zir LM, Miller SW, Dismore RE et al. Interobserver variability in coronary arteriography. Circulation 1976;53:627.

[10] Goldberg RK, Kleiman NS, Minor ST et al. Comparison of quantitative coronary angiography to visual estimates of lesion severity pre and post PTCA. Am Heart J $1990 ; 178$.

[11] Waters D, Lesperance J, Craven TE, Hudson G, Gillam LD. Advantages and limitations of serial coronary arteriography for the assessment of progression and regression of coronary atherosclerosis. Implications for clinical trials. Circulation 1993;87(Suppl.):1I-38.

[12] Buchwald H, Matts JP, Fitch LL et al. for the Surgical Control of the Hyperlipidaemias (POSCH) Group. Changes in sequential coronary angiograms and subsequent coronary events. J Am Med Assoc 1992;268:1429.

[13] Applegate RJ, Herrington DM, Little WC. Coronary angiography: more than meets the eye. Circulation 1993;87:1399. 
[14] Vos J, de Feyter PJ, Simoons ML, Tijssen JGP, Deckers JW. Retardation and arrest of progression or regression of coronary artery disease: A review. Prog Cardiovasc Dis 1993;35:435.

[15] Brown BG, Hillger LA, Lewis $\mathrm{C}$ et al. A maximum confidence approach for measuring progression and regression of coronary artery disease in clinical trials. Circulation 1993;87(Suppl.):II-66.

[16] Badimon L, Badimon JJ, Gold HK, Fuster V. Coronary atherosclerosis: Morphology and characteristics to identify by evolving imaging technology. Am J Card Imag 1992:6:278.

[17] Waller BF, Pinkerton CA, Slack JD. Intravascular ultrasound: A historical study of vessels during life: the new 'gold standard' for vascular imaging. Circulation 1992; $85: 2305$.

[18] de Feyter PJ, Serruys PW, Davies MJ, Richardson P Lubsen J, Oliver MF. Quantitative coronary angiography to measure progression and regression of coronary atherosclerosis: Value, limitations, and implications for clinical trials. Circulation 1991;84:412.

[19] Stone PH, Gibson CM, Pasternak RC et al. for the Harvard Atherosclerosis Reversibility Project Study Group. Natural history of coronary atherosclerosis using quantitative angiography in men, and implications for clinical trials of coronary regression. Am J Cardiol 1993;71:766.

[20] Waller BF. Anatomy, histology, and pathology of the major epicardial coronary arteries relevant to echocardiographic imaging techniques. J Am Soc Echo 1989;2:232.

[21] Grodin CM, Dyrda I, Pasternac A, Campeau, Bourassa MG Lesperance J. Discrepancies between cineangiographic and postmortem findings in patients with coronary artery disease and recent myocardial revascularization. Circulation 1974;49:703.

[22] Schwartz JN, Kong Y, Hackel DB, Bartel AG. Comparison of angiographic and postmortem findings in patients with coronary artery disease. Am J Cardiol 1975;36:174.

[23] Hutchins GM, Buckley BH, Ridolfi RL et al. Correlation of coronary arteriograms and left ventriculaograms with postmortem studies. Circulation 1977;56:32.

[24] Arnett RN, Isner JM, Redwood D. Coronary artery narrowing in coronary heart disease. Comparison of cineangiographic and necropsy findings. Ann Intern Med 1979;36:174.

[25] Leung WH, Alderman EL, Lee TC, Stadius ML. Quantitative arteriography of apparently normal coronary segments with nearby or distant disease suggests presence of occult, nonvisualized atherosclerosis. J Am Coll Cardiol $1995 ; 25: 311$.

[26] Zijlstra F, van Ommeren J, Reiber JHC, Serruys PW. Does quantitative assessment of coronary artery dimensions predict the physiological significance of coronary stenosis? Circulation 1987;75:1154.

[27] Harrison DG, White CW, Hiratzka LF et al. The value of lesion cross-sectional area determined by quantitative coronary angiography in assessing the physiologic significance of proximal left anterior descending arterial stenoses. Circulation 1984;69:1111.

[28] Marcus ML, Armstrong ML, Heistad DD, Eastham CL, Mark AL. Comparison of three methods of evaluating coronary obstructive lesions: Postmortem arteriography, pathologic examination and measurement of the regional myocardial perfusion during maximal vasodilation. Am J Cardiol 1982;49:1699.

[29] White CW, Wright CB, Doty DB et al. Does visual interpretation of the coronary angiogram predict the physiologic importance of a coronary stenosis? N Engl J Med 1984;310:819.

[30] Ellis S, Sanders W, Goulet C et al. Optimal detection of the progression of coronary artery disease: Comparison of methods suitable for risk factor intervention trials. Circulation 1986;76:1235.

[31] St Goar FG, Pinto FJ, Alderman EL, Fitzgerald PJ Stadius ML, Popp RL. Intravascular ultrasound imaging of angiographically normal coronary arteries: An in vivo comparison with quantitative angiography. J Am Coll Cardiol 1991;18:952.

[32] St Goar FG, Pinto FJ, Alderman EL et al. Detection of coronary atherosclerosis in young adult hearts using intravascular ultrasound. Circulation 1992;86:756.

[33] St Goar FG, Pinto FJ, Alderman EL et al. Intracoronary ultrasound in cardiac transplant recipients: In vivo evidence of 'angiographically silent' intimal thickening. Circulation 1992;85:979.

[34] Yamagishi M, Miyatake K, Tamai J, Nakatani S, Kojama $J$, Nissen SE. Intravascular ultrasound detection of atherosclerosis at the site of focal vasospasm in angiographically normal or minimally narrowed coronary segments. J Am Coll Cardiol 1994;23:352.

[35] Hermiller JB, Buller CE, Tenaglia et al. Unrecognized left main coronary artery disease in patients undergoing interventional procedures. Am J Cardiol 1993;71:173.

[36] Nissen SE, Gurley JC, Grines $\mathrm{CL}$ et al. Intravascular ultrasound assessment of lumen size and wall morphology in normal subjects and patients with coronary artery disease. Circulation 1991;84:1087.

[37] Yock PG, Linker DT. Intravascular ultrasound: Looking below the surface of vascular disease. Circulation 1990;81:1715.

[38] Di Mario C, The SHK, Madretsma $S$ et al. Detection and characterization of vascular lesions by intravascular ultrasound: An in vitro study correlated with histology. J Am Soc Echo 1992;5:135.

[39] Mintz GS, Popma JJ, Pichard AD et al. Patterns of calcification in coronary artery disease: A statistical analysis of intravascular ultrasound and coronary angiography in 1155 lesions. Circulation 1995;91:1959.

[40] Friedrich GJ, Moes NY, Muehlberger VA et al. Detection of intralesional calcium by intracoronary ultrasound depends on the histologic pattern. Am Heart J 1994;128:435.

[41] Pignoli P, Tremoli E, Poli A, Oreste P, Paoletti R. Intimal plus medial thickness of the arterial wall: $A$ direct measurement with ultrasound imaging. Circulation 1986;74:1399. 
[42] McPherson DD, Sirna SJ, Hiratzka LF et al. Coronary arterial remodeling studied by high-frequency epicardial echocardiography: An early compensatory mechanism in patients with obstructive coronary atherosclerosis. J Am Coll Cardiol 1991;17:79.

[43] Hausmann D, Erbel R, Alibelli-Chemarin MJ et al. The safety of intracoronary ultrasound: A multicenter survey of 2207 examinations. 1995;91:623.

[44] Di Mario C, Madrestma S, Linker D et al. The angle of incidence of the ultrasonic beam: A critical factor for the image quality in intravascular ultrasound. Am Heart $\mathbf{J}$ 1993; 125:442.

[45] Benkeser PJ, Churchwell AL, Lee C, Abouelnasr DM. Resolution limitations in intravascular ultrasound imaging. J Am Soc Echocardiogr 1993;6:158.

[46] Glagov S, Weisenberg E, Zaris CK, Stancunavicus R Kolettis GJ. Compensatory enlargement of human atherosclerotic coronary arteries. $\mathrm{N}$ Engl J Med 1989;316:1371.

[47] Armstrong ML, Warner ED, Connor WE. Regression of coronary atheromatosis in rhesus monkeys. Circ Res 1970;27:59.

[48] Armstrong ML, Heistad DD, Marcus ML, Megan MB, Piegors DJ. Structural and hemodynamic response of peripheral arteries of macaque monkeys to atherogenic diet. Arteriosclerosis 1985;5:336.

[49] Stiel GM, Stiel LSG, Schofer J, Donath K, Mathey DG. Impact of compensatory enlargement of atherosclerotic coronary arteries on angiographic assessment of coronary artery disease. Circulation 1989;80:1603.

[50] Gibbons GH, Dzau VJ. The emerging concept of vascular remodeling. N Engl J Med 1994;330:1431.

[51] Mc Pherson DD; Sirna SJ, Hiratzka LF et al. Coronary arterial remodeling studied by high-frequency epicardial echocardiography: An early compensatory mechanism in patients with obstructive coronary atherosclerosis. J Am Coll Cardiol 1991;17:79.

[52] Steinke W, Els T, Hennerici M. Compensatory carotid artery dilatation in early atherosclerosis. Circulation 1994;89:2578.

[53] Gerber TC, Erbel R, Görge G, Ge J, Rupprecht H-J Meyer J. Extent of atherosclerosis and remodeling of the left main coronary artery determined by intravascular ultrasound. Am J Cardiol 1994;73:666.

[54] Ge J, Erbel R, Zamorano J et al. Coronary artery remodeling in atherosclerotic disease: An intravascular ultrasonic study in vivo. Cor Art Dis 1993;4:981.

[55] Hermiller JB, Tenaglia AN, Kisslo $\mathrm{KB}$ et al. In vivo validation of compensatory enlargement of atherosclerotic coronary arteries. Am J Cardiol 1993;71:665.

[56] Losordo DW, Rosenfield K, Kaufman J, Pieczek A, Isner JM. Focal compensatory enlargement of human arteries in response to progressive atherosclerosis. In vivo documentation using intravascular ultrasound. Circulation 1994;89:257.

[57] Pasterkamp G, Wensing PJW, Post MJ, Hillen B, Mali
WPTM, Borst C. Paradoxical arterial wall shrinkage may contribute to luminal narrowing of human atherosclerotic femoral arteries. Circulation 1995;91:1444.

[58] Glagov S, Zaris C, Giddens DP, Ku DN. Hemodynamics and ahterosclerosis. Arch Pathol Lab Med 1988;112:1018.

[59] Langille BL, O'Donnell F. Reductions in arterial diameter produced by chronic decreases in blood flow are endothelium-dependent. Science 1986;231:405.

[60] Vita JA, Treasure CB, Ganz P, Cox DA, Fish RD, Selwyn AP. Control of shear stress in the epicardial coronary arteries of humans: Impairment by atherosclerosis. J Am Coll Cardiol 1989;14:1193.

[61] Hausmann D, Goupta M, Connolly AJ, Paemley WW Fitzgerald PJ, Yock PG. Accuracy of intravascular ultrasound to assess progression and regression of experimental aortic atherosclerosis (abstr). Circulation 1993;88:I-501.

[62] Gupta M, Connolly AJ, Zhu BQ et al. Quantitative analysis of progression and regression of atherosclerosis by intravascular ultrasound: Validation in a rabbit model (abstr). Circulation 1992;86:I-518.

[63] Lassetter JE, Krall RC, Moddrelle DS, Jenkins RD. Morphologic changes of the arterial wall during regression of experimental atherosclerosis (abstr). Circulation 1992;86:I-518.

[64] Kovach JA, Mintz GS, Kent KM et al. Serial intravascular studies indicate that chronic recoil is an important mechanism of restenosis following transcatheter therapy (abstr). J Am Coll Cardiol 1993;21:484A.

[65] Mintz GS, Kovach JA, Pichard AD et al. Geometric remodeling is the predominant mechanism of clinical restenosis after coronary angioplasty (abstr). J Am Coll Cardiol 1994;23:138A.

[66] Di Mario C, Gil R, Camenzind E et al. Quantitative assessment with intracoronary ultrasound of the mechanisms of restenosis after percutaneous transluminal coronary angioplasty and directional coronary atherectomy. Am J Cardiol 1995;75:772.

[67] Roelandt JRTC, Di Mario C, Pandian et al. Three-dimensional reconstruction of intracoronary ultrasound images: Rationale, approaches, problems and directions. Circulation 1994;90:1044.

[68] von Birgelen C, Di Mario C, Li W et al. Volumetric quantification in intracoronary ultrasound: Validation of a new automatic contour detection method with integrated user interaction (abstr). Circulation 1994;90:I-550.

[69] Dhawale PJ, Rasheed Q, Berry J, Hodgson J McB. Quantification of lumen and plaque volume with ultrasound: Accuracy and short term variability in patients (abstr). Circulation 1994;90:I-164.

[70] Dhawale PJ, Rasheed Q, Mecca W, Nair R, Hodgson J $\mathrm{McB}$. Analysis of plaque volume during DCA using a volumetrically accurate three-dimensional ultrasound technique (abstr). Circulation 1993;88:I-550.

[71] Rosenfield K, Losordo DW, Ramaswamy K, Isner JM. Three-dimensional reconstruction of human coronary and 
peripheral arteries from images recorded during two-dimensional intravascular ultrasound examination. Circulation 1991;84:1938.

[72] Cavaye DM, White RA, Lerman RD et al. Usefulness of intravascular ultrasound imaging for detecting experimentally induced aortic dissection in dogs and for determining the effectiveness of endoluminal stenting. Am J Cardiol 1992;69:705.

[73] Schryver TE, Popma JJ, Kent KM, Leon MB, Mintz GS. Use of intracoronary ultrasound to identify the true coronary lumen in chronic coronary dissection treated with intracoronary stenting. Am J Cardiol 1992;69:107.

[74] Coy KM, Park JC, Fishbein MC, Laas T et al. In vitro validation of three-dimensional intravascular ultrasound for the evaluation of arterial injury after balloon angioplasty. J Am Coll Cardiol 1992;20:692.

[75] Mintz GS, Leon MB, Popma JJ, Kent KM. Three-dimensional reconstruction of endovascular stents (abstr). J Am Coll Cardiol 1992;19:224A.

[76] Prati F, Di Mario C, von Birgelen C et al. Usefulness of on-line 3D reconstruction for stent implantation (abstr). J Am Coll Cardiol 1995;25:9A.

[77] Mintz GS, Keller MB, Fay FG. Motorized IVUS transducer pull-back permits accurate quantitative axial measurements (abstr). Circulation 1992;86:I-323.

[78] Di Mario C, von Birgelen C, Prati F et al. Three-dimensional reconstruction of two-dimensional intracoronary ultrasound: Clinical or research tool? $\mathrm{Br}$ Heart $\mathrm{J}$ 1995;73(Suppl.2):26.

[79] Rosenfield K, Kaufman J, Pieczek A, Langevin RE, Razvi S, Ilsner JM. Real-time three-dimensional reconstruction of intravascular ultrasound images of iliac arteries. Am J Cardiol 1992;70:412.

[80] Chandrasekaran K, D'Adamo AJ, Sehgal CM. Three-dimensional reconstruction of intravascular ultrasound images. In: Yock PG, Tobis JM, (eds), Intravascular Ultrasound Imaging, New York: Churchill-Livingston, $1992 ; 141$.
[81] Kitney R, Moura L, Straughan K. 3-D visualization of arterial structures using ultrasound and voxel modelling. Int $\mathrm{J}$ Cardiac Imag 1989;4:135.

[82] Hausmann D, Friedrich G, Sudhir K et al. 3D intravascular ultrasound imaging with automated border detection using 2.9 F catheters (abstr). J Am Coll Cardiol 1994;23:174A.

[83] Prati F, Di Mario C, von Birgelen $C$ et al. On-line automated lumen volumen measurement with $3-\mathrm{D}$ intracoronary ultrasound during coronary interventions (abstr). J Am Coll Cardiol 1995;25:345A.

[84] Li W, von Birgelen C, Di Mario C et al. Semi-automated contour detection for volumetric quantification of intracoronary ultrasound. Proc Comput Cardiol, IEEE Computer Society Press, Los Alamitos, 1994;267.

[85] von Birgelen C, Di Mario C, Li W et al. Clinical Application of a new computerized method measuring coronary artery dimensions by three-dimensional intracoronary ultrasound: Reproducibility in-vivo during coronary interventions (abstr). Eur Heart J 1995;16: 428.

[86] Galli FC, Sudhir K, Kao AK, Fitgerald PJ, Yock PG. Direct measurement of plaque volume by three-dimensional ultrasound: Potential and pitfalls (abstr). J Am Coll Cardiol 1992;19:115A.

[87] Dhawale PJ, Wilson DL, McB Hodgson J. Optimal data acquisition for volumetric intracoronary ultrasound. Cathet Cardiovasc Diagn 1994;32:288.

[88] Slager CJ, Laban M, von Birgelen C et al. ANGUS: A new approach to three-dimensional reconstruction of geometry and orientation of coronary lumen and plaque by combined use of coronary angiography and IVUS (abstr). J Am Coll Cardiol 1995;25:144A.

[89] von Birgelen C, Umans V, Di Mario C et al. Mechanism of high-speed rotational atherectomy and adjunctive balloon angioplasty revisited by quantitative coronary angiography: edge detection versus videodensitometry. Am Heart J 1995;130:405. 